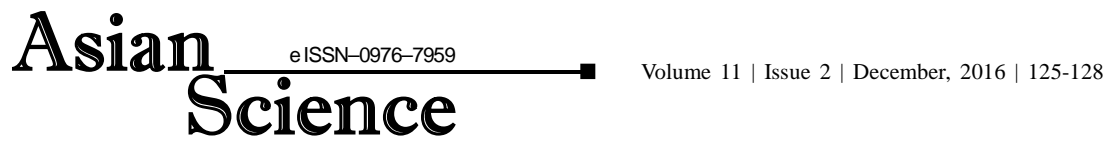

\section{Constraints associated with the use of weather forecasting service}

\author{
RAJESH*, A. K. GODARA, C. D. AUTADE AND S. K. MEHTA \\ Department of Extension Education, College of Agriculture, Chaudhary Charan Singh Haryana Agriculture University, \\ HISAR (HARYANA) INDIA (Email: charudattautade@ gmail.com)
}

\begin{abstract}
There is great need of sustainable management in the agricultural sector of the world economics. Accurate and timely forecast of rainfall pattern and other weather variable continue still be a major challenge and preoccupation for the scientific community to sustain the agricultural development. The dictionary meaning of constraints are 'confinement', the exercise to force to determine or 'confine action, 'bound' and 'flattered condition' and restriction of liberty. The major constraints in using the weather forecasting information as may be seen from the table. The possible reasons as reported by the respondents for these problems are as follows: Absence of location specific weather forecasts was the major problem because the forecasts usually cover a wider area and speculation exists among farmers. Poor reliability of weather forecasts was a problem because of lack of certainty of information. Hence, farmers lack trust in the forecasts. One of the most serious constraint was that mostly weather forecasting was not timely forecast at the time of flood and drought and success rate was also very low. Corinne et al. (2000) reported that many felt that weather pattern in Andean semi and region had changed and traditional indicators were not as they were in the past. However, they have not been replaced or modified to date. Constraints regarding the understand ability of weather forecasting information. It was found that belief about weather forecast was more powerful than modern weather forecasting in farmer's view was one of the most serious constraints. All the constraints can be minimized by providing guidance to the farmers and by distribution literature and training regarding technicality of weather forecasting advisory services to the farmers.
\end{abstract}

Key Words : Constraints associated, Weather forecasting service

View point paper : Rajesh, Godara, A. K., Autade, C. D. and Mehta, S. K. (2016). Constraints associated with the use of weather forecasting service. Asian Sci., 11 (2): 125-128, DOI : 10.15740/HAS/AS/11.2/125-128.

\footnotetext{
* Author for correspondence

Rajesh, Department of Extension Education, College of Agriculture, Chaudhary Charan Singh Haryana Agriculture University, HISAR (HARYANA) INDIA
} 